\title{
De la fundamentación teórica a la lectura científico-técnica del mensaje cartográfico
}

\author{
Dra. Ruth Miranda Guerrero* \\ DR. JOSÉ SANCHO COMINS **
}

\begin{abstract}
RESUMEN
\section{ABSTRACT}

En este trabajo se pretende realizar

The first part of this paper considers una aproximación a dos temáticas concretas; la primera de ellas hace referencia a la reflexión teórica sobre

la Expresión Cartográfica y su estructuración; en la segunda se expone un guión metodológico para el análisis y valoración de mapas temáticos, denominado científicotécnico, $y$ se aportan los resultados

obtenidos tras su aplicación al discurso cartográfico de la variable temática clima en los Atlas Nacionales de España, Cuba y México. theoretical aspects of cartographic visualization. The second part presents methodological guidelines for analysing and evaluating thematic maps. Results are then applied to the mapping of climatic variables used in the National Atlases of Spain, Cuba and Mexico.

KEY WORDS:

National Atlas of Spain, Cuba and Mexico, climate, cartographic layout, scientific and technical method.

PALABRAS CLAVE: Atlas Nacionales de España, Cuba y México, discurso cartográfico, clima, Expresión Cartográfica, método cientifico-técnico.
\end{abstract}

* E-mail: ruth.miranda@uah.es. Prołesora Asociada. Departamento de Geografía. Universidad de Alcalá

** E-mail: jose.sancho@uah.es. Catedrático de Análisis Geográfico Regional. Departamento de Geografia. Universidad de Alcalá. 


\section{INTRODUCCIÓN}

A través de este artículo pretendemos que el lector se aproxime a una cuestión habitualmente poco considerada por los investigadores: el análisis y valoración de los Atlas Temáticos. El discurso gráfico del territorio, analítico y sintético, que se construye con el apoyo de los mapas, encuentra su máximo exponente en este tipo de obras. Podemos decir que algunos Atlas son magníficos representantes de itinerarios complejos que ponen a la luz la capacidad creadora de sus autores y los avances en torno a temáticas muy variadas (clima, demografía, turismo, problemas medioambientales, paisaje, etc.). La tipología más sencilla de los Atlas Geográficos nos permite diferenciarlos según su componente espacial (ámbito geográfico y escalas de representación), el perfil temático (estructuración semántica y sintáctica), o el soporte de presentación (componente técnico). Esta última característica, que agrupa a los Atlas como impresos y electrónicos, multimedia o Atlas en la Web (el medio más innovador dentro de las Tecnologías de la Información Geográfica), manifiesta la evolución técnica y actualidad de este tipo de obras.

El análisis de los Atlas puede abordarse desde diferentes enfoques. Los resultados obtenidos de tales estudios seguramente ayudarían a construir metodologías de análisis y establecer, incluso una Teoria de los Atlas que explique, tras una discusión formal, los avances tecnológicos en la producción de mapas temáticos y las diversas opciones de expresión cartográfica de contenidos específicos.

En este trabajo se presentan los resultados obtenidos en la valoración del discurso cartográfico del clima de tres Atlas Nacionales (España, Cuba y México). Se ha elegido una variable temática de gran tradición en Cartografía con el fin de experimentar una propuesta metodológica (científicotécnica) en la que venimos trabajando últimamente (Miranda y Sancho, 2000; Miranda, 2000).

Respecto a la elección de los tres Atlas Nacionales citados, cabe decir que obedece a dos razones; la primera, el interés personal por tres documentos de importancia cartográfica cercana; y la segunda, la relación y experiencias que compartieron los responsables de los tres Atlas durante la ejecución de sus proyectos cartográficos. Este último motivo podria explicar un cierto aire de homogeneidad en los planteamientos y soluciones de problemas. Esta circunstancia quizá nos impediría conocer otras opciones y estudiar otro tipo de soluciones cartográficas, sin embargo, como podrá verse, la heterogeneidad de los ámbitos geográficos tratados suple con creces esa aparente "monotonía cartográfica", enfrentando a los autores a desafíos que repercuten directamente en el ingenio cartográfico. 
Dicho esto, señalamos que los tres Atlas Nacionales tienen por objetivo la caracterización geográfica del territorio al que hacen referencia. La estructura temática de los tres Atlas es de tipo clásica, regida por los objetivos científicos, técnicos, operativos y culturales que se plantean en cada proyecto cartográfico y expresados en sus respectivas presentaciones.

\section{LA FUNDAMENTACIÓN METODOLÓGICA}

Dos grandes fases suelen sucederse habitualmente a la hora de presentar nuevas iniciativas en el terreno metodológico. La primera fase -teórica- se centra en la estructuración o formalización de los componentes conceptuales básicos de la Expresión Cartográfica, y la segunda -práctica- comprende el planteamiento y aplicación del método de estudio que ha sido propuesto previamente.

- Estructuración de la Expresión Cartográfica:

Para definir el método de valoración que hemos dado en llamar científico-técnico partimos de la revisión de los aspectos teóricos de la Expresión Cartográfica. Este apartado de la Cartografía está cobrando actualmente notable importancia (Peterson, 1995; Taylor, 1985, 1996; Krygier, 1996; Kraak and Ormeling, 1996; Dorling y Fairbairn, 1997, Cartwright, Peterson, Gartner, 1999); a todos estos autores parece muy conveniente apoyar la investigación en esta fundamentación teórica. En este artículo no nos vamos a detener, sin embargo, en los nuevos medios de presentación de la información geográfica (Atlas Electrónicos y Atlas en la Web) que por su importancia bien merecen la redacción de un nuevo trabajo.

Del estudio de los aspectos teóricos de la Expresión Cartográfica se dedujo una relación de temas a tener en cuenta en el análisis cartográfico que, como se verá más adelante, hemos estructurado en cuatro grandes bloques. Con ello conseguimos plantear un esquema metodológico que contempla a la mayoria de elementos a considerar. Este trabajo previo se estimó necesario porque, si bien el estudio de los fundamentos de la Expresión Cartográfica es un tema bastante conocido, sabemos de algunas imprecisiones de términos que convenía aquilatar para tener un mayor rigor en un terreno pragmático.

Nuestra propuesta merece un análisis más amplio y nos gustaría que los interesados en estos temas la vieran tan solo como una invitación para profundizar en esta materia. Consideramos que esto es necesario para empezar a sintetizar un cuerpo teórico que permita sentar las bases de 
una Teoría de los Atlas. Es sabido que existen numerosas aportaciones dedicadas a la reflexión teórica de la Expresión Cartográfica y, sin embargo, ninguna que aborde los Atlas con cierta profundidad. La mayoría de estas investigaciones son manuales generales y algunas de ellas se han visto rebasadas por las nuevas tecnologías, las cuales exigen otras soluciones científico-técnicas en las que es necesario poner atención.

Un primer aspecto a tener en cuenta radica en los caminos de percepción que la Teoría de la Imagen explica con suficiente profundidad. Su significación en el campo de la lectura de imágenes cartográficas ha resultado muy fructífera (fig. 1).

El proceso perceptivo-cognitivo de imágenes cartográficas ayuda a entender cómo la mente, después de distinguir y ordenar una serie de estímulos (sensación), los complementa y acompaña de un grupo de sensaciones que solidifica e integra de forma tal que constituyen la expresión y conocimiento aparentemente próximo de un objeto presente con una determinada posición en el espacio.

Todas las sensaciones dejan en el sistema nervioso una especie de huella a partir de la cual puede resurgir el conocimiento de los objetos, aun cuando los órganos sensoriales no sean impresionados directamente por tales objetos. A la vivencia o producción de dicho conocimiento se le llama imagen. Para que las imágenes contenidas en un mapa pasen a ser algo más que una sensación, es necesario que el usuario consiga su interpretación, lo que se logrará sólo si éste cuenta con los antecedentes suficientes de lectura cartográfica (fig. 1).

Así, la información que pueda extraer una persona del mapa que esté utilizando, será probablemente al principio confusa e inestable, destacando tan solo las sensaciones que estén más "vivas". Por ejemplo, si se trata de un mapa turístico en el que se han representado los monumentos históricos con los símbolos que el usuario está acostumbrado a identifi-

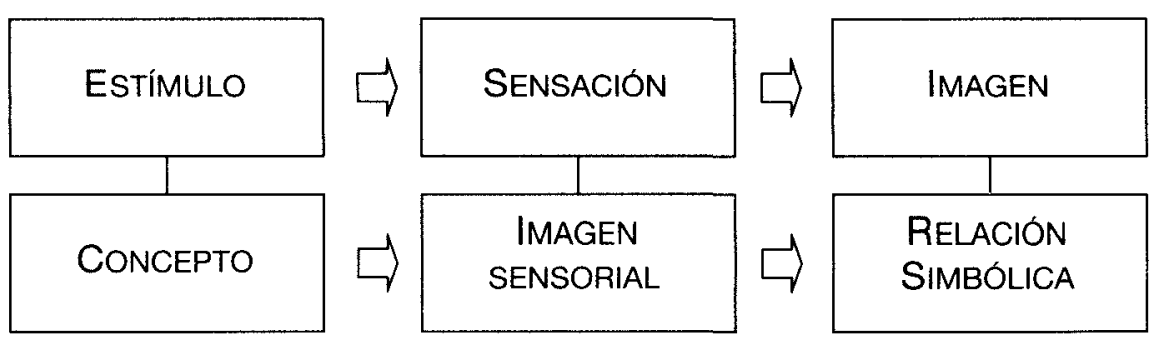

Fig. 1. Proceso de percepción y significación cartográfica. 
carlos, las primeras sensaciones coincidirán con esta apreciación fácil; pero no por esto ni por el número de sensaciones simultáneas entenderá de forma espontánea los fenómenos representados y su relación espacial, porque este acto se asocia con otro proceso psíquico, el cognoscitivo. Este es el que ajusta en toda su profundidad el significado de conceptos, imagen y relación simbólica.

Un segundo apartado corresponde estrictamente a la Comunicación Cartográfica. En este caso, el modelo propuesto toma en consideración los nuevos soportes cartográficos y las formas de comunicación. Gracias a los avances tecnológicos, el modelo de comunicación cartográfico permite la interacción entre autores, datos y usuarios (proceso de retroalimentación), de tal manera que el mapa pasa a ser un medio de comunicación directo y, como señala Peterson (1995), el ordenador deja de ser sólo el instrumento para elaborar mapas y pasa a ser el medio de comunicación (fig. 2).

Este modelo de comunicación cartográfica puede ser contemplado desde cuatro puntos de vista:

A) Actividad de los interlocutores: incluye al emisor o cartógrafo, éste se encarga de elaborar el mapa y tiene por objetivo transmitir el mensaje al destinatario o receptor (usuario del mapa). Para el cartógrafo el receptor y el medio de comunicación son los condicionantes más importantes del proceso comunicativo (fig. 2).

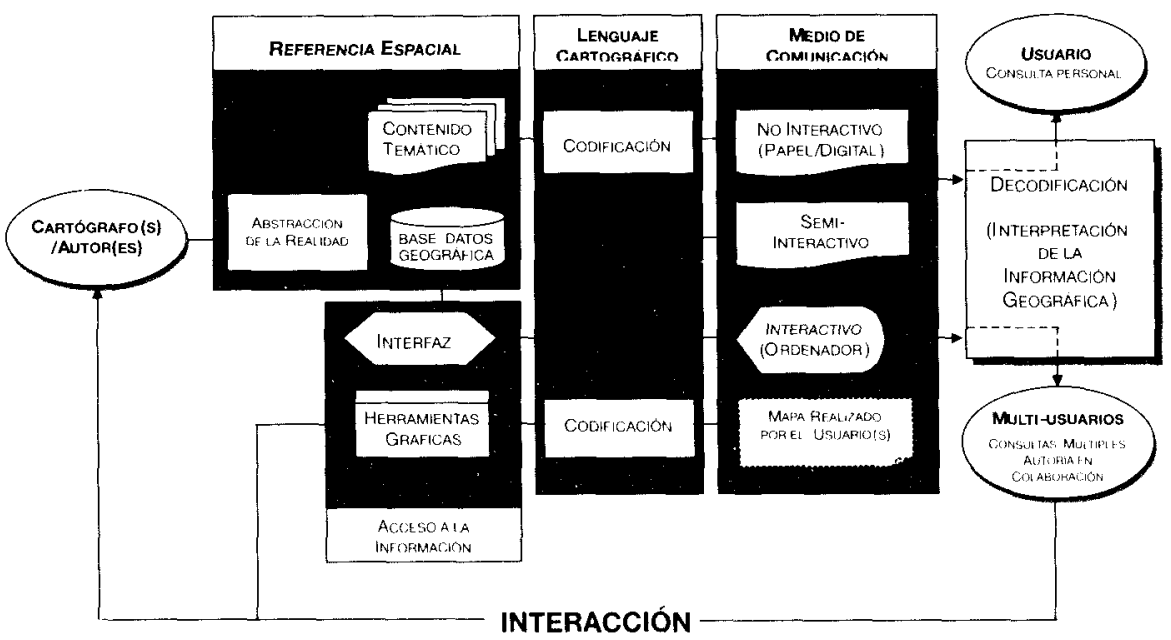

Fig. 2. Modelo de comunicación cartográfica. 
B) Contexto: implica la referencia espacial, es decir, la realidad geográfica del cartógrafo almacenada en una Base de Datos Geográfica (BDG) y de la cual se extraen las variables temáticas a cartografiar, bien sea por el cartógrafo (mapa no interactivo y semi-interactivo) o por el usuario (mapa semi-interactivo o interactivo) (fig. 2).

C) Código: el tema que se representa en el mapa es el mensaje que el autor desea expresar. El código posee dos modalidades, la primera es el sistema codificador que cifra el mensaje y se compone de los símbolos y las variables visuales elegidas por el autor para la construcción del sistema de representación (varía según la temática a cartografiar). La segunda modalidad será el sistema decodificador, su función es descifrar el mensaje a partir del código utilizado. Todo mapa cuenta con una leyenda o notas aclaratorias que auxilian a la decodificación del mensaje e interpretación de su contenido informativo (fig. 2).

D) Soporte: la elección de éste depende del cartógrafo, condicionado por los objetivos informativos, técnicos y de comunicación. Así el mapa puede ser: (a) No interactivo, cuando el usuario hace consultas de tipo personal (tradicionalmente su soporte es el papel, pero también los hay digitales). (b) Semi-interactivos, los que cuentan con una interfaz que permite al usuario cierto poder de decisión para consultar y, en algunos casos, diseñar mapas, comúnmente su soporte es el CD-ROM. (c) Interactivos, que como su nombre indica, son productos de interacción con la información y con el cartógrafo. Incorporan un mecanismo que responde a una interfaz que permite al usuario participar activamente en el proceso comunicativo. Su soporte es la computadora, las consultas son multi-usuarios y toleran la autoría en colaboración. Son llamados también "hipermapas" (fig. 2).

El tercer bloque de aspectos teóricos a considerar en la Expresión Cartográfica es el relativo al Lenguaje Cartográfico. En este se distinguen tres niveles: en el primero están los elementos cartográficos (símbolos y variables visuales) -haciendo una analogía con el lenguaje escrito podemos decir que aquellos son las "vocales" y "consonantes"-, en el segundo nivel cabe distinguir los sistemas de implantación y que, continuando con la analogía, los identificamos como las "formas de escritura" (palabras) - dichas formas pueden ser de tipo puntual, lineal, areal y en los casos especiales de volumen (aparente o real) -; el tercer nivel le corresponde a los sistemas de representación (cartogramas, coropletas, isopletas, etc.) -estos sistemas equivalen al denominado "texto cartográfico" en términos analógicos, resultado de las combinaciones realizadas con los dos primeros- (fig. 3). 


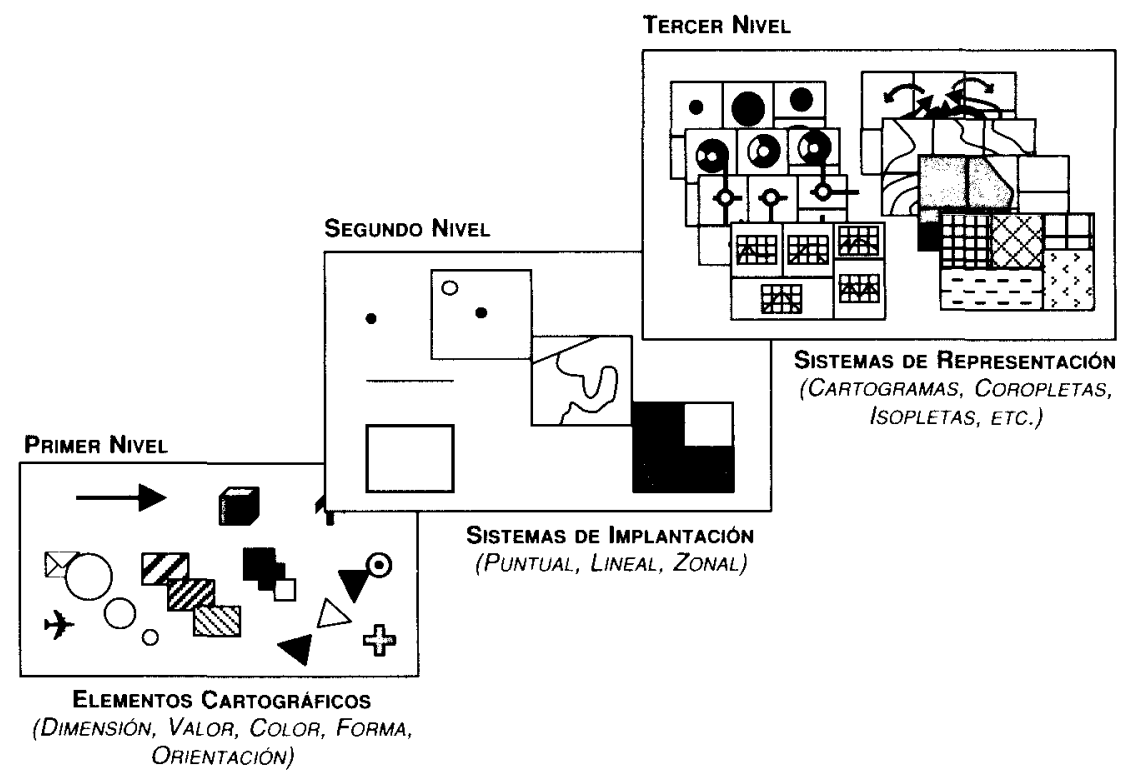

Fig. 3. Estructura del lenguaje cartográfico.

Un cuarto bloque parece diferenciarse en la teoria de la Expresión Cartográfica: el Diseño Cartográfico que, como se sabe, es la manifestación técnico-artística de la obra cartográfica. En nuestro caso, cabe señalar el impacto de las nuevas tecnologías que han abierto posibilidades espectaculares en un campo inédito denominado Visualización Geográfica (VG) o Cartografía Científica.

En términos tecnológicos, la VG es un sistema informatizado en el que a partir de bases de datos geográficas (BDG), algoritmos y tecnología se combinan fácilmente diferentes variables. Además, el sistema permite que investigadores emplazados en distintos sitios puedan acceder a una terminal, consultar las BDG, realizar rápidamente simulaciones, hacer cálculos diversos y diseñar productos cartográficos. No obstante, el modelo del sistema de la VG implica que el usuario sea capaz de identificar y definir el problema cartográfico (exploración-verificación), buscar y evaluar métodos adecuados de análisis y expresión (síntesis cartográfica), elegir diferentes soluciones gráficas y ejecutarlas antes de pasar a la etapa de producción definitiva (diseño). Esta suma de capacidades se vuelve muy exigente para unos usuarios, hoy por hoy, altamente especializados en alguna de las facetas señaladas pero no en todas ellas. Ello supone una fuerte limitación. 


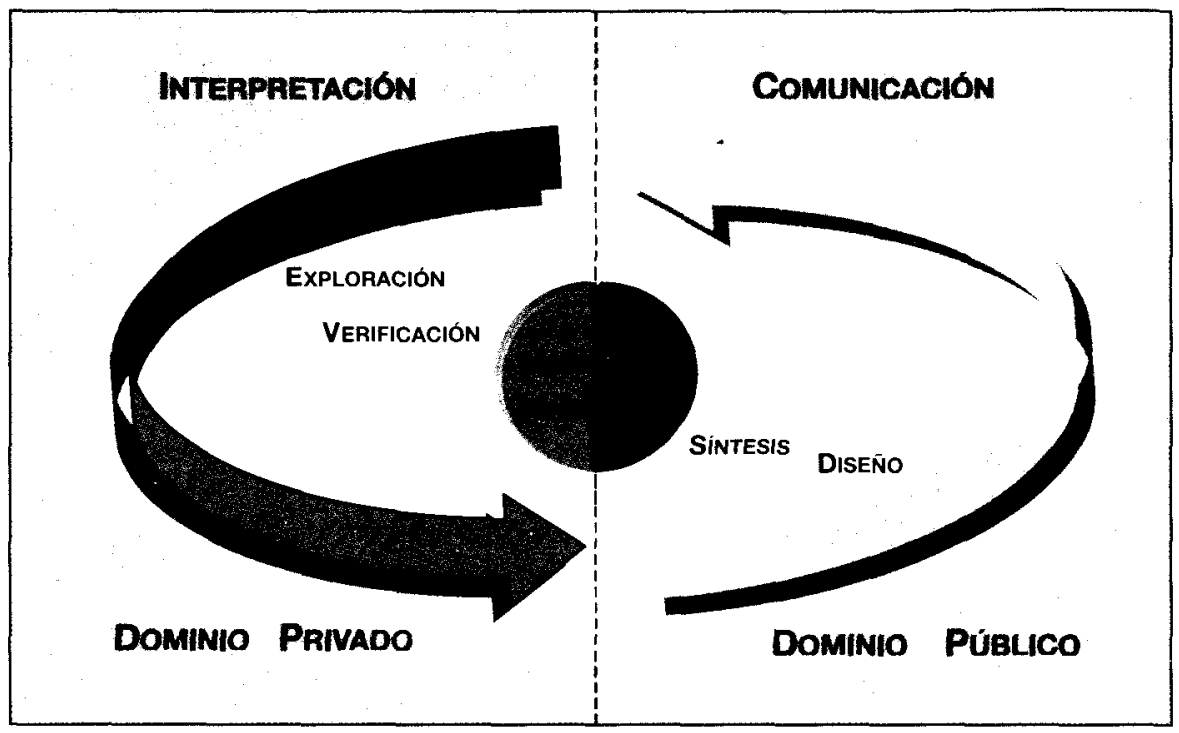

Fig. 4. Modelo de visualización elaborado a partir del de DiBiase (en Dorling y Fairbairn, 1997).

En suma, la reflexión efectuada hasta ahora sobre los fundamentos de la Expresión Cartográfica nos permite contar con un cuerpo teórico coherente en el que se puede enmarcar nuestra metodología de análisis y valoración. Insistimos en señalar que, aunque se tenga la impresión de ser un tema agotado para la investigación científica, en la praxis se echan en falta estudios formales al respecto, por ejemplo para conciliar tipologias de símbolos, de variables visuales y de sistemas de representación, o formalizar nuevos diseños cartográficos (multimedia e hipermedia).

- Formulación de un método de análisis cartográfico:

Como ya mencionamos, y de acuerdo a los postulados teóricos anteriores, proponemos una estructura metodológica - denominada científicotécnica (Miranda y Sancho, 1999; Miranda, 2000; Miranda y Echamendi, 2001) - que puede resultar útil para la lectura y análisis de obras cartográficas. Quizás se note en nuestra propuesta un cierto caríz didáctico que es comprensibie por nuestra profesión docente. En el siguiente esquema se muestran las etapas de dicho método (fig. 5).

Cada etapa del guión metodológico expuesto se centra en uno de los aspectos que la teoría de la Expresión Cartográfica contempla, realizando 


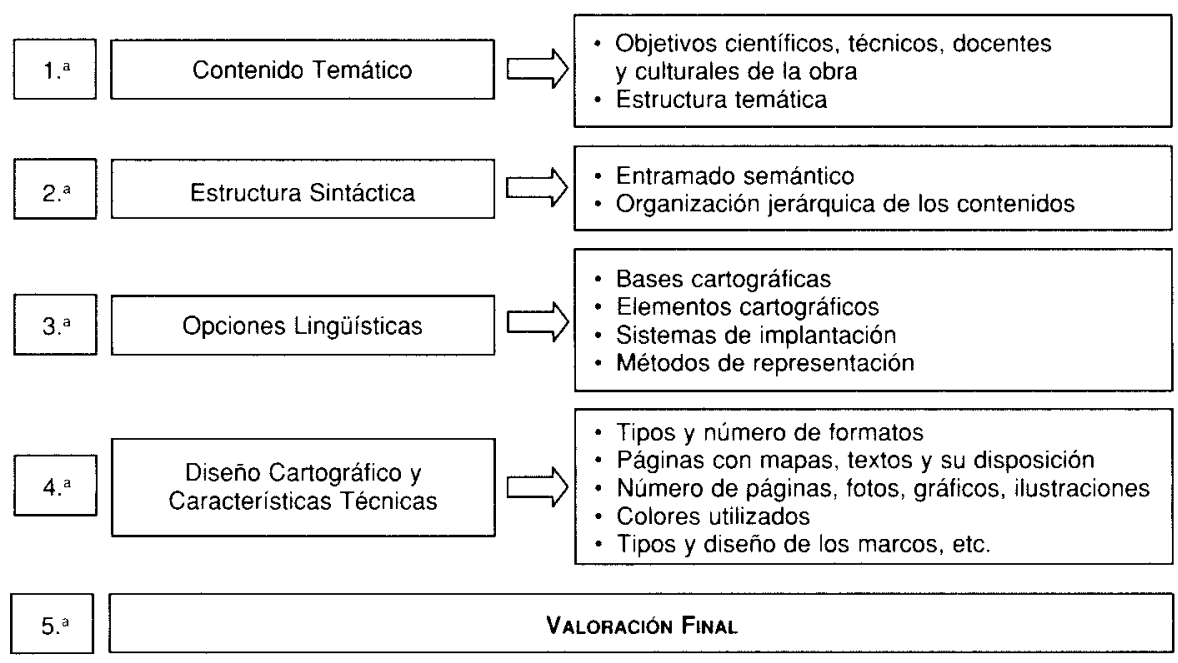

Fig. 5. Etapas del método científico-técnico.

al final una valoración global de la calidad del discurso cartográfico. En la primera se estudia el tipo de objetivos del proyecto cartográfico y su grado de cumplimiento; además, se hace una presentación de los contenidos específicos. En la segunda etapa se analiza el entramado sintáctico del documento, es decir, la organización jerárquica de los contenidos y su orden lógico-temático. La tercera etapa se dedica a revisar la calidad de las bases cartográficas, el nivel de generalización y los componentes del lenguaje cartográfico. En la cuarta etapa centramos nuestra atención en el diseño de la obra y sus características técnicas. Con los resultados obtenidos hasta entonces se está en condiciones de abordar la última fase, en donde se emiten los juicios de valoración global del discurso cartográfico que arma la obra.

\section{LA APLICACIÓN METODOLÓGICA}

Una vez establecida la metodología, fruto de la reflexión teórica, vamos ahora a realizar una aplicación de la misma al análisis de los discursos cartográficos de la variable clima de los tres Atlas Nacionales citados en la introducción. Los resultados de este análisis los referiremos a continuación en cuatro bioques: (a) contenido temático, (b) estructuración sintáctica, (c) opciones lingüísticas y (d) diseño cartográfico. Para seguir los comentarios de valoración, sería recomendable tener a la mano los tres Atlas Naciona- 
les. Dicha recomendación tiene una doble justificación; por un lado, nuestros juicios podrán seguirse con mayor facilidad, ya que en este documento no es posible incluir la serie cartográfica en cuestión; y por otro, el lector tendrá la posibilidad de conocer tres obras cartográficas muy importantes, que han marcado la pauta en su género en los últimos años. No obstante, tampoco resultará estéril al lector seguir con atención nuestro análisis, aun sin contar con la presencia de dichos Atlas Nacionales, pues siempre se podrán extraer ideas sugerentes para una aplicación propia.

\subsection{Contenido Temático}

Un proyecto cartográfico tan complejo como un Atlas Nacional involucra diversas actividades durante su realización y una heterogeneidad de puntos de partida o perspectivas; los de carácter geográfico-científico se reflejan en su estructura temática.

Podemos decir que, comparando los tres Atlas, el de Cuba es más rico en contenido, prueba de ello es la serie de mapas de cartografía aplicada y el de "regionalización climática" (NANC, p. VI.4.2), en donde convergen diversas variables de tipo sintético. Otro ejemplo, son los mapas de precipitación cartografiados para dos periodos de referencia (1931-1972 y 1964-1983) que favorecen la comprensión de este elemento climático en su dimensión temporal y, en especial, la representación de "eventos notables" (NANC, p. VI.3.4) que narran los tres huracanes que azotaron fuertemente el país, el de 1963 (Flora), el de 1979 (Frederick) y el de 1982 (Alberto). Estos, relacionados con el mapa de "trayectoria de huracanes de gran intensidad entre 1844-1985" (NANC, p. VI.3.4) y la serie de mapas de "situaciones sinópticas" (NANC, p. VI.2.1), ayudan a comprender la vulnerabilidad del país frente a estas perturbaciones meteorológicas, que se manifiestan en el verano y otoño, y que son propias de la zona de circulación tropical (perturbaciones ondulatorias del flujo del Este y ciclones), por la posición geográfica del archipiélago cubano dentro del sistema de arcos del Caribe-Antillano.

Otra forma de ver comparativamente los contenidos de los tres documentos es a través de la lectura de sus leyendas. Por medio de éstas se puede establecer una jerarquía según las temáticas cartografiadas, la expresión informativa y las categorías o rangos presentados. Así, el primer puesto por la abundancia de contenidos es para el Atlas de Cuba, el segundo para el de México y el tercero para el de España.

La mayoría de los mapas del Atlas cubano presentan más de un tipo de información; es decir, las leyendas son complejas, relacionan varios con- 
tenidos informativos como sucede en los mapas de acampos de presión y vientos de enero y de julio" (NANC, p. VI.2.3), en los que se incluye la frecuencia (porcentaje) y velocidad $\left(\mathrm{Km} / \mathrm{h}^{-1}\right)$ del viento, las rosas de los vientos (velocidad media sin calmas en $\mathrm{Km} / \mathrm{h}^{-1}$ y calmas en porcentaje) y la presión atmosférica (hectopascales). También se pueden nombrar los de "regionalización climática sobre las bases de calor sofocante y los de la base del régimen térmico" (NANC, p. VI.4.2 y 4), entre otros. Sin embargo, hay que decir que la lectura de algunas leyendas de estos mapas no son fáciles, se requiere de parte del lector un conocimiento científico relativamente profundo de la variable tratada, hecho que nos hace pensar más bien en que son mapas dirigidos a especialistas en el tema, interesados en la planificación de actividades socioeconómicas.

Del contenido del Atlas de Cuba también destacan los índices cartografiados, como el del "coeficiente de humedecimiento de Ivanov" (NANC, p. VI.4.1) para establecer cuatro grados de humedecimiento medio anual: insuficiente (estepa), moderado (estepa-bosque), suficiente (bosque suficientemente húmedo) y abundante (bosque húmedo) y que tiene como indicador a la vegetación natural. Otro es el del "rendimiento industrial de la caña de azúcar" (NANC, p. VI.4.3) con el que se evaluaron las condiciones óptimas potenciales, considerando la precipitación durante el periodo de zafra. La caña de azúcar es el principal cultivo de este país, razón de la importancia que se le concede en el Atlas; el mapa resultante refleja que casi todo el territorio cubano presenta condiciones adecuadas para el desarrollo de este cultivo, aunque el mapa de "agricultura cañera" (NANC, XVII.1.4) muestre las zonas específicas ocupadas por este cultivo en la actualidad. En el texto introductorio se comenta esta observación y se advierte la necesidad de tener en cuenta otras limitaciones como las edáficas y no únicamente las climáticas, cómo es lógico suponer.

En el atlas de México también se cartografiaron varios índices, como los de aridez. Aunque, en este caso, quizás hubiera sido preferible presentar un único índice de aridez, el que mejor refleje el balance hídrico del país en lugar de tres, puesto que los cartografiados expresan casi el mismo resultado y pueden aportar una información confusa, además de redundante. Alguno de estos mapas podría sustituirse por uno que mostrara los sitios que registraron precipitaciones mensuales inferiores a la media esperada, o alguno de evapotranspiración. Estos mapas indican la irregular distribución de la escasez de lluvia en México, destacando por la pobreza pluviométrica la planicie costera de los estados de Sonora y Sinaloa, la Altiplanicie Septentrional y la Meridional, la península de Baja California y la depresión del río Balsas; también complementan a los cuatro mapas de la hoja "canícula, sequia intraestival o de medio verano" (del grupo 
Agroclimatología, IV.5.1) y a los dos de la hoja "zonas susceptibles a desastres por fenómenos naturales" (del grupo Estado de los Componentes Naturales del Medio Ambiente, V.2.9), en los que se considera la variable temporal para reflejar la problemática de las sequías que afectan fuertemente al sector agrario mexicano.

La mayor parte del maíz - cereal básico de la alimentación mexicana- se cultiva en tierras de temporal (cultivo de secano), muchas veces en asociación con el frijol -la más importante leguminosa cultivada en México-. Las especies más comunes de frijol son trepadoras, aprovechándose de la caña de maíz como apoyo. De esta forma se cosechan los dos alimentos básicos desde tiempos prehispánicos. La producción de ambos es más o menos variable, dependiendo si el año es seco o lluvioso. La distribución de las lluvias va de junio a mediados de octubre, antecedidas por un periodo de transición en mayo de lluvias irregulares (aguaceros de mayo); hay un periodo corto de sequía en agosto, cuando éste se prolonga (canícula) los daños son irreparables.

Un tema afín en los tres Atlas es la precipitación. Con respecto a la manera de cómo fue tratada esta variable, cabe advertir que en el Atlas de España los mapas de precipitación se refieren a un periodo de 20 años, en el de Cuba se consideraron dos series estadísticas de 42 y de 20 años, y en el de México una serie de 60 años de observaciones. Esto indica, básicamente, los periodos de referencia de las series estadísticas que disponían los autores en el momento que se ejecutó cada proyecto y el estado de las estadísticas meteorológicas oficiales de cada país.

Para el Atlas español se elaboraron 33 mapas de precipitación, para el de Cuba 17 y para el de México 16. Los tres Atlas tienen un mapa de precipitación media anual pero en el de México, además de la media aritmética, se cartografió la probabilidad de que se presenten precipitaciones iguales o mayores a la media. Esto es importante porque el valor medio para México puede dar una idea errónea del recurso pluviométrico; para tener una percepción correcta es preciso consultar este mapa y los de los valores mensuales - que en el Atlas se refieren a la moda y no a la media- dado que las desigualdades de distribución del recurso pluviométrico y su gran variabilidad interanual están íntimamente ligadas a la conformación de los distintos paisajes mexicanos.

En el Atlas de España se representó la precipitación media mensual y las máximas y mínimas absolutas, mapas que en los Atlas de México y Cuba no se incluyen. Si bien en estos dos se cartografió el "coeficiente de variación de la precipitación anual's (razón entre la desviación típica y la media) con el que se matizan los resultados medios anuales (NANC, 
VI.3.1; ANM, p. IV.4.6). En el texto introductorio del Atlas de España se apunta la importancia de este índice, señalando que la "media tiene mucho de artificial'», si bien no se realizó un mapa con esta información. Consideramos que este mapa debería incluirse en futuras ediciones del Atlas, dada la variabilidad interanual de las aportaciones de agua de lluvia en España.

Otros mapas interesantes de los tres Atlas son los de días con precipitación superior a $1 \mathrm{~mm}$. En el Atlas de México y en el de Cuba se representó el promedio anual y en el de España los promedios estacionales. Con esta serie de mapas en el Atlas español se expresa la variación estacional de la lluvia a lo largo del año y, a su vez, se detalla la variabilidad en la distribución del número de días con precipitación. Estos mapas se parecen a los de la distribución media mensual y anual, es decir, indican claramente que la precipitación y el número de días con lluvias en España desciende de norte a sur aumentando en las zonas montañosas.

Como se observa, el interés de esta variable es grande en los tres Atlas y la solución particular de cada uno obedece, principalmente, a las condiciones geográficas propias del país. En Cuba, en el Caribe, predominan las condiciones tropicales marítimas y la corresporıdiente distribución estacional de las lluvias. México está cortado por el Trópico de Cáncer, que lo delimita en dos zonas, la tropical y extratropical. Los contrastes orográficos en ambas provocan modificaciones tan fuertes que es necesario tener en cuenta la existencia de numerosos microclimas. Ambos países están entre la zona anticiclónica y la de calmas ecuatoriales y son afectados por los vientos alisios. España debe sus características climáticas a la variación estacional de influencia de la subsidencia anticiclónica subtropical y la circulación general del Oeste en zona templada. En el verano los anticiclones son responsables de cielos soleados, temperaturas elevadas y ausencia de lluvias, y en el invierno, cuando las altas presiones retroceden a latitudes menores, la circulación general del Oeste se impone y las borrascas frontales polares se presentan, aportando al territorio español la mayor parte de las precipitaciones e influyendo en el descenso de las temperaturas.

Según lo que acabamos de decir habrá temas de especial interés para cada país, como por ejemplo la representación de los días con nieve para España, que de cara a la actividad turística es muy importante, sin contar lo que significa este tipo de precipitación en el abastecimiento de agua. Otro ejemplo son los mapas de regionalización agroclimática "del rendimiento agrícola y del industrial de la caña de azúcar" (NANC, XVII.1.4) de Cuba que, como se indicó, es el producto base del renglón industrial del país. 
Por último, cabe citar algunos comentarios referentes a los contenidos temáticos acertadamente incluidos en alguno de los tres Atlas y que sería conveniente anotarlos de cara a una siguiente edición. El mapa de la «red de estaciones meteorológicas" (NANC, p. VI.1.3; ANM, p. IV.4.1) aparece en los Atlas de Cuba y México y no en el de España, hecho que consideramos importante, sobre todo para complementar los comentarios que se presentan en el texto introductorio y notas explicativas que acompañan a algunos mapas. Dichos comentarios serían más fáciles de seguir y muy esclarecedores de las informaciones cartográficas referidas en los mapas, dado que el conocimiento de la ubicación de los puntos de registro que se señalan en los textos ayudarían a entender sucesos especiales como, por ejemplo, los sitios del país que observaron las temperaturas más bajas en 1971 (Riaño, $-23{ }^{\circ} \mathrm{C}$; Villafría, $-22{ }^{\circ} \mathrm{C}$; Villanublada, $-18,8^{\circ} \mathrm{C}$, etc., $\mathrm{p}$. 9.16-17) (ANE, p. 17). Igualmente están los mapas de cartografía aplicada elaborados para el Atlas de Cuba y que para los atlas de España y México podrian haber tenido su sentido (regionalización agroclimática y confort climático, NANC, p. VI.4.3).

Además, como se sabe, en los tres países la orografía es uno de los factores más importantes para entender sus condiciones climáticas; por ello aquella, debería estar representada en estos mapas, ya sea por medio de un sombreado, isolíneas o cotas, según lo permita la legibilidad de la información temática y las características del diseño. Esta información da mayor sentido a la distribución de las variables representadas. Por ejemplo, los mapas de «temperaturas del aire mínimas y máximas diarias" de Cuba (NANC, VI.2.4) están directamente asociadas al factor altitudinal, es decir, las llanuras costeras (mín. $25^{\circ}-25^{\circ} \mathrm{C}$; máx. $25^{\circ}-35^{\circ} \mathrm{C}$ ), las llanuras interiores (mín. $15^{\circ}-25^{\circ} \mathrm{C}$; máx. $30^{\circ}-35^{\circ} \mathrm{C}$ ) y la montaña (mín. $15^{\circ}-20^{\circ} \mathrm{C}$; máx. $20^{\circ}-30^{\circ} \mathrm{C}$ ), relación que también se presenta en los mapas de los otros dos Atlas.

Por último, cabe decir que los tres Atlas cumplen sobradamente con los objetivos científicos planteados. Nuestras apreciaciones respecto a los contenidos temáticos se derivan de las propias soluciones observadas en los tres Atlas al hacer el análisis comparativo.

\subsection{Estructuración Sintáctica}

En este epígrafe se analiza el entramado sintáctico de los tres Atlas, su organización jerárquica y las relaciones intercartográficas. De esta manera entramos en el análisis del discurso cartográfico. 
La estructura temática de los tres Atlas es de tipo clásico. En la tabla siguiente se resume su organización sintáctica. El orden que se presenta en la tabla es el propio de cada documento y como se puede ver, tanto el Atlas de España como el de Cuba comienzan con el mapa de "clasificación climática», en cambio el de México cierra la sección con éste. La solución del Atlas mexicano nos parece la mejor, pues una vez expuestos los diferentes componentes físicos del clima, el mapa de clasificación del clima se ofrece como una imagen integradora de éste.

Grandes grupos temáticos de la sección clima de los tres Atlas Nacionales

\begin{tabular}{|c|c|c|}
\hline Atlas de España & Atlas de Cuba & Atlas de México \\
\hline 1. Clasificación Climática & $\begin{array}{l}\text { 1. }{ }^{\circ} \text { Zonificación, } \\
\text { Regionalización y } \\
\text { Clasificación Climática }\end{array}$ & $100^{\circ}$ Climas \\
\hline & 2. Redes de Observación & \\
\hline $\begin{array}{l}\text { 7. Horas de Sol Despejado } \\
\text { 8. Radiación Solar }\end{array}$ & $\begin{array}{l}\text { 3. Días Despejados e } \\
\text { Insolación } \\
44^{\circ} \text { Radiación Solar }\end{array}$ & $\begin{array}{l}\text { 1. Observatorios, Estaciones } \\
\text { Meteorológicos e } \\
\text { Insolación }\end{array}$ \\
\hline $\begin{array}{l}\text { 9. Presión y Vientos } \\
11 .{ }^{\circ} \text { Situaciones Sinópticas }\end{array}$ & $\begin{array}{l}\text { 6. Presión y Vientos } \\
\text { 5. } \text { Situaciones Sinópticas } \\
\text { y Trayectoria } \\
\text { de los Huracanes }\end{array}$ & $\begin{array}{l}\text { 2. Viento Dominante durante } \\
\text { el Año } \\
\text { 3. Energía del Viento } \\
\text { Dominante }\end{array}$ \\
\hline 4. ${ }^{\circ}$ Temperatura & 7..$^{\circ}$ Temperaturas & $\begin{array}{l}\text { 4. }{ }^{\circ} \text { Temperatura Media } \\
5 .^{\circ} \text { Temperaturas Extremas }\end{array}$ \\
\hline $\begin{array}{l}\text { 2. } \\
3^{\circ} \text { Precipitación } \\
\text { 5. Hidrometeoros } \\
\text { 6. Humedas Relativa } \\
.^{\circ} \text { Evaporación }\end{array}$ & 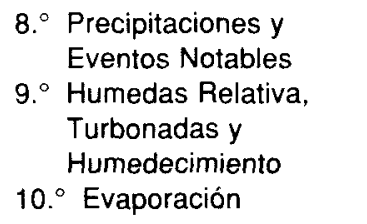 & $\begin{array}{l}\text { 6. Precipitación } \\
\text { 7. Otros Fenómenos } \\
\text { Climáticos } \\
\text { 8. Valor más Frecuente } \\
\text { de la Precipitación } \\
\text { Mensual y Anual }\end{array}$ \\
\hline $100^{\circ}$ Isocronas & $11 .^{\circ}$ Cartografía Aplicada & 9. Medidas de Aridez \\
\hline
\end{tabular}

Fuente: Elaboración propia a partir del NANC, 1989; ANE, 1992; ANM, 1992.

Nota: El número indica el orden en el que aparecen en la sección del clirna los diferentes grupos temáticos en cada Atlas.

A continuación se presentan las maquetas de los tres Atlas. Estos esquemas ayudan a visualizar la estructura general de los tres documentos.

Si bien el mapa de "Climas" del Atlas de México está bien situado en el contexto general del capítulo, cabe decir que presenta problemas de lectura. Se cartografiaron 122 tipos climáticos y la decodificación de las 122 fórmulas y la correspondencia de los recintos no es tarea fácil. El lec- 


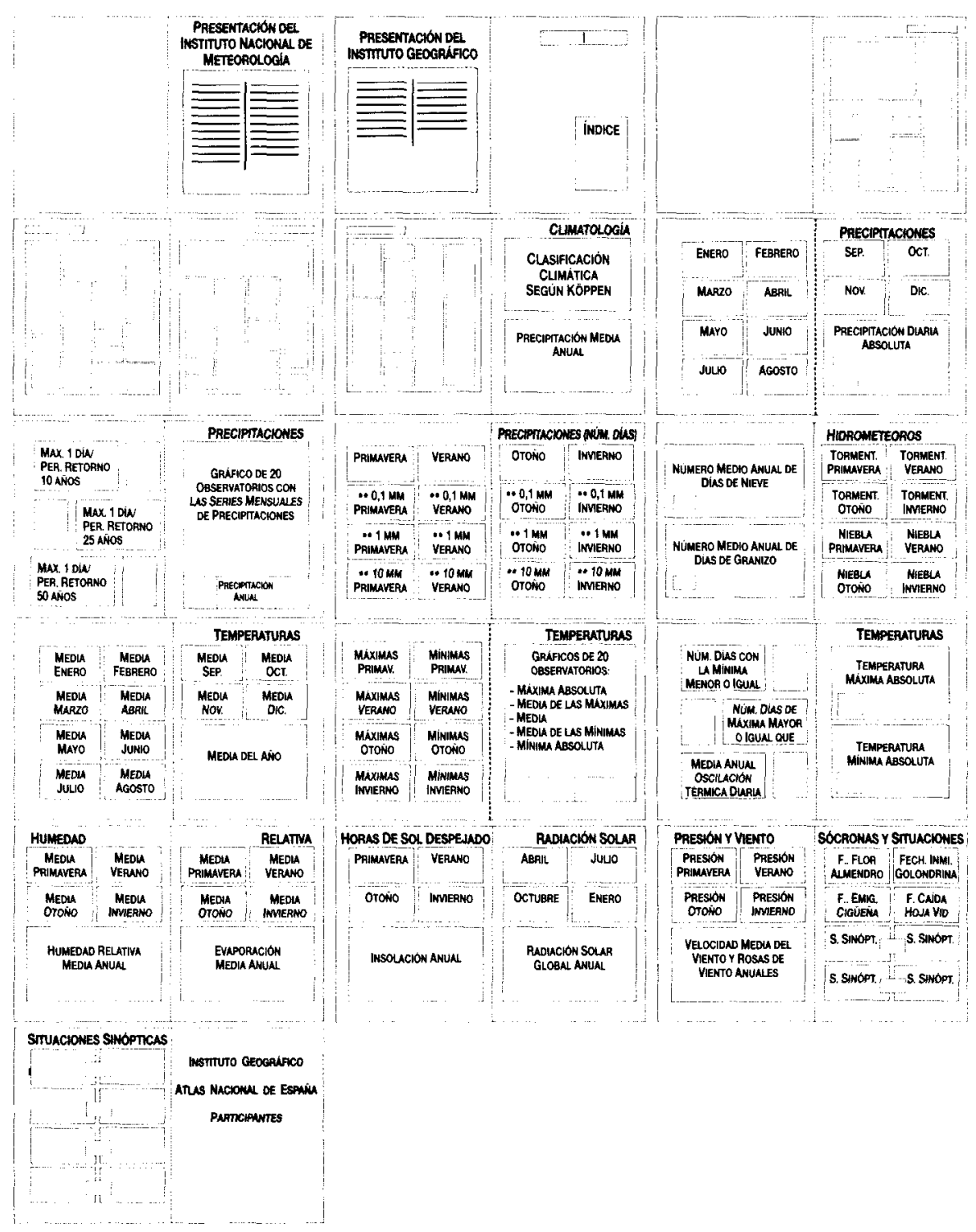

Fig. 6. Maqueta del Cuadernillo de Climatologia del Atlas Nacional de España.

tor debe asociar las fórmulas a colores y tramas diferentes, siendo muy compleja esta tarea. Sería recomendable en una segunda edición presentar en el reverso de la hoja las tablas que detallen los tipos y subtipos cli- 
cians

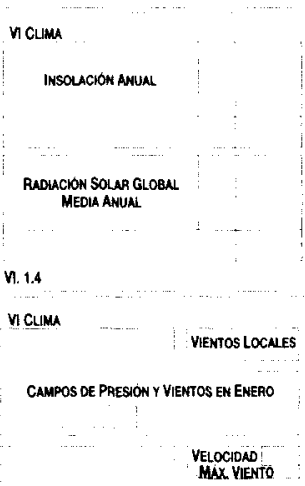

CAMPOS DE PRESIONY YVIENTOS EN JULLO

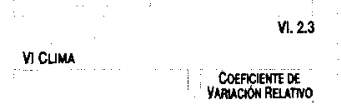

PRECIPTIACION MEDIA EN E PERIODO LLUVOSOS. 1931-1972 (MAYO-OCTURAE)

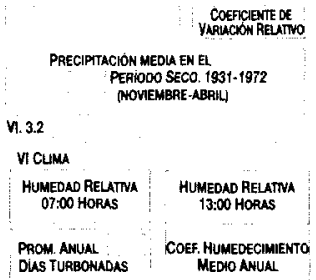

ENAPORACIOH MEDUA ANUAL

V. 4.1

vi cume

\section{romounowersin}

REgIONALZZACION ClLMATHCA SOBRE

LA BASE DEL REGLMEN TÉRAMICO

\section{Rararsoscumitos}

RegionauZZACION CLMMATIGA GENERAL n cum

REgIONALIZACIÓN CLIMÁTICA LEYENDA Y TJPOS DE CLIMAS

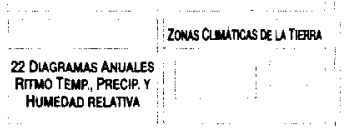

V. 1.2

n cums

STUUACIONES SIHOPTICAS

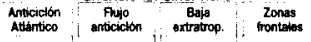

Anticiclón Dobot Onda Muracán

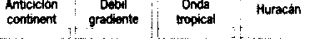

TRAYECTORU DE LOS HURACANES DE GAAN INTENSIDAD QUE HWN AZOTADO A CUBA 184-70es

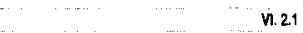

n cuma

TEMPERATURA MEDIA ANUAL DEL ARE

TEMP. MEOLA DEL AaRe TEMP. MEDIA deL AaRe EN ENERO (INVERANO) EN JUUO NERANO)

Dufacion ANUa PEF. Fecha de PLSO de CON TEMP. $<25^{\circ} \mathrm{C}$ TEMP MEDUS $<25^{\circ} \mathrm{C}$

ท. 2.4

vicuma

PRECIPTACION MEDIA ANUNL. 1964-83

PRECIP. MEOLAS
EN EL PERIODO
PEERIODO MEDLO EN EL

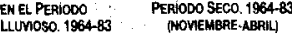

LLUNOSO. 1964-83

v. 3.3

V CLIMA

REgIOHALITACYON CUMATCA SOBRE LA BLSE OE LAS REgLOHALITACYON GLIMATCA SOBRE LA BLSE OE LAS
CONDHCHONES DE BHENESTAR Y CNIOR SOFOCANTE

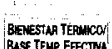
BuSE TEUP. EFECTWA
EOUNALETE ENERO

BVEETLAR TERauco

SOBPE UA RASE DE

V., 4.2
REOES DE OBSERYACION METEOROLOGICA

FAECUENCLA DE DUAS DESPEJADOS

v. 1.3

VI Cuma

COWDICIONES DE U CIRCULACION ATMOSFERICA

TIPO DE CIRCULACIÓN EN SUPERFICIE

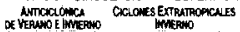

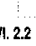

V. 2.2

vicuma

MEDU TEMP. IEMP MAX ABS ANUAL MAX. ABS. ANUALES PELLA\% DE

MED. TEMP MIIN : TEMP MIN Aas ANUUL ABSOLLTAS ANUNLES DEL $5 \%$ DE PAOB.

\section{ANUALES}

COEE VARIACIÓN
PRECLP.

ANUALES
PRECIPTACOON MEDIA ANUAL 1931-72

PBom NunN DEDUS

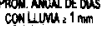

V Cuma

: RIMMO ANUNA DE

FECHA DE COMEENZO US PRECIPTTACIONES PURACION DEL

PERiodo lluNioso

PRECA Mix DURL

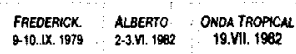

V.. 3.4

VI CLIMA

CONDHCIONES CLIMATITAS ANUANES PARA LA VIDA DE LA POBLACION

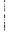

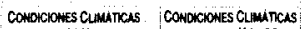
PAT VIOA DELA T PABA VIOA DE LA Poglacion II POELACSOCH

REg AGAOCLmisca REG AGROCUMATCA

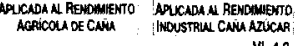

Fig. 7. Maqueta de la sección clima del Nuevo Atlas Nacional de Cuba. 


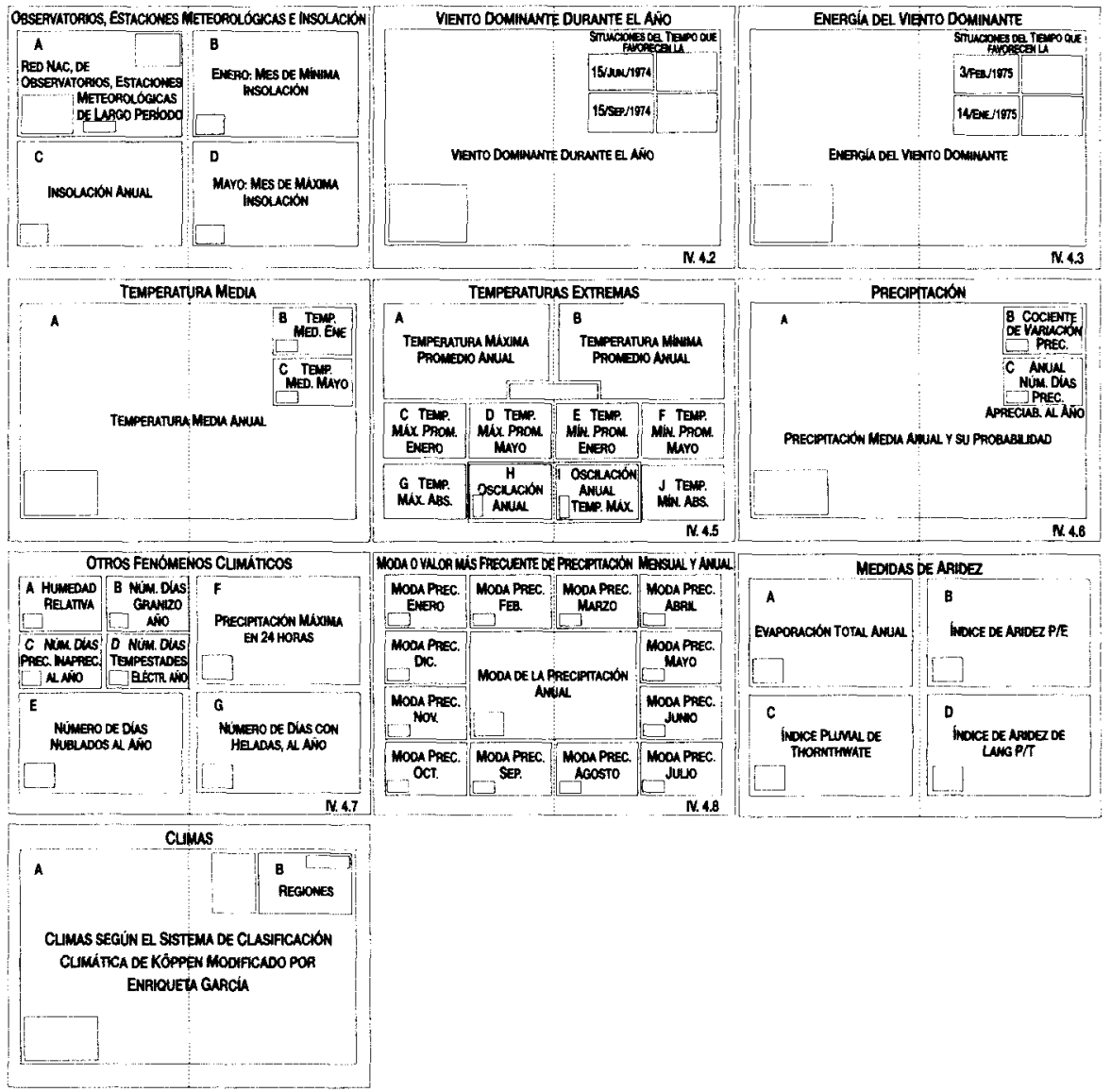

Fig. 8. Maqueta de la sección clima del Atlas Nacional de México.

máticos que propone la autora, adaptando el sistema de Köppen para las condiciones de México.

Los Atlas de España y Cuba comienzan con un texto introductorio en el que se describen las características climáticas del país. Después de esta breve explicación viene la serie cartográfica "desnuda» en el Atlas de Cuba, mientras que el Atlas español cuenta con algunos textos explicativos que acompañan a los mapas. Esta estructuración no la tiene el Atlas mexicano, este optó por la solución de hojas independientes que expresan cartográficamente aspectos específicos de la variable temática "clima". Desde este punto de vista, si comparamos los tres documentos, el Atlas mexicano se diferencia notablemente del español y cubano, tal di- 
ferencia algunos pueden considerarla una deficiencia, pues no cuenta con los textos -introductorio o colateral a los mapas - que apoyen la interpretación de los contenidos representados en los mapas, además de una orientación didáctica para los lectores inexpertos en la lectura de mapas temáticos.

\subsection{Opciones Lingüísticas}

Como es sabido, el correcto uso del lenguaje cartográfico contribuye al cumplimiento de una de las funciones de toda obra cartográfica: comunicar. Un mapa no sólo debe dar prueba de cualidades de fondo, si no también de forma, técnica y didáctica.

Según el número de mapas y las escalas utilizadas, el Atlas español (111 mapas y 4 escalas distintas) presenta una menor variabilidad con respecto a los Atlas mexicano (52 mapas y 4 escalas diferentes) y cubano (66 mapas y 11 escalas distintas) (gráfico 1).

Es importante señalar que uno de los problemas del Atlas de Cuba es precisamente esta diversidad de escalas que pueden ocasionar problemas si se desea comparar rápidamente distintos mapas. Un ejemplo son los mapas de "precipitación media en el periodo seco. 1931-72" y "precipitación media en el periodo lluvioso. 1931-72" elaborados a escala 1:2.000.000 (NANC, p. VI.3.2), mientras que los análogos de 1964-83 se cartografiaron a 1:3.000.000 (NANC, p. VI.3.3). Como sabemos, en un Atlas es frecuente presentar la información con diferente nivel de detalle, no obstante para la variable que se analiza, creemos que hubiera sido conveniente utilizar la misma escala según valor medio representado (precipitaciones mensuales, estacionales, anuales). Esta solución es la del Atlas Nacional de España, en éste todos los mapas de valores medios anuales se cartografiaron a escala 1:4.500.000, con lo cual se hace rápida su comparación.

Respecto a los elementos cartográficos (símbolos y variables visuales), como vemos en el gráfico 2, los autores de los tres Atlas utilizaron ampliamente la variable visual valor (leyendas de uno o dos tonos a distinta intensidad), y en algunos mapas cubanos y mexicanos, en los que se combinaron dos o más variables temáticas, además del «valor» se emplearon las tramas (implantación zonal) o una mayor variedad de símbolos (implantación puntual). Otra solución que destacamos de las series cartográficas es el uso de la variable "saturación" en los Atlas de Cuba y México. Nos referimos a los mapas de variables continuas y leyendas am- 


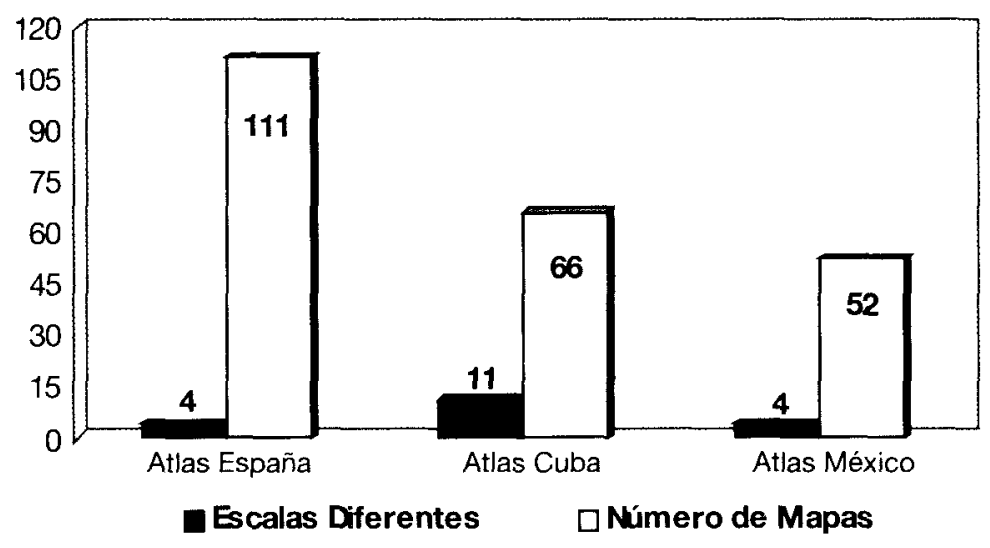

Gráfico 1. Relación entre el número de mapas y las escalas utilizadas.

plias, en los que se decidió saturar varios tonos para dar el efecto de aumento o disminución de los valores temáticos representados.

Podemos decir que de acuerdo con la temática representada, la variedad y riqueza de símbolos puntuales y lineales obedeció a las soluciones sintéticas, las cuales son más numerosas en el Atlas de Cuba que en los otros dos Atlas.

En cuanto a los sistemas de implantación, la relación porcentual entre los tres Atlas para los de tipo zonal es casi similar, donde se marca una

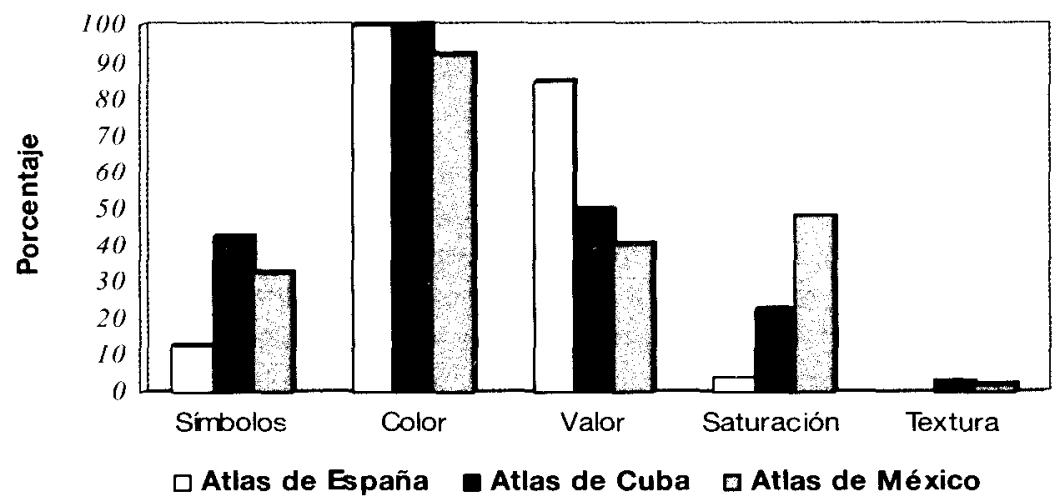

Gráfico 2. Utilización de elementos cartográficos. 
notable diferencia es en el sistema puntual y su asociación, como resultado de la representación de dos o más variables temáticas en un mismo mapa; por ejemplo, hay algunos mapas de símbolos proporcionales de implantación puntual sobre una base coroplética -como el de "regionalización climática sobre las bases de calor sofocante y los de la base del régimen térmico" (NANC, p. VI.4.2 y 4)-O de símbolos geométricos nominales sobre una base isoplética acompañados, en algunos casos, de isolíneas (gráfico 3).

En lo referente a los sistemas de representación, las diferencias porcentuales se mantienen al ser estos la "conjunción: elementos cartográficos-datos-sistemas de implantación" (gráfico 4). De éstos destacamos los sistemas de "uso único" que nombramos así por ser sistemas que sólo aparecen en alguno de los tres Atlas. Los cartodiagramas de barras (C1) y los cartogramas de símbolos proporcionales (C2) del Atlas de Cuba son un buen ejemplo de mapas estadísticos con información puntual, donde se compararán dos o más variables o se expresarán datos de intervalos.

Otro sistema presente en la serie cartográfica del Atlas de México y Cuba es el de coropletas $\mathrm{C}(2)$. De acuerdo con las características de la variable temática en cuestión (clima) las coropletas arrojar, lógicamente, un valor porcentual muy bajo, ya que se trata de la expresión de una variable física asociada a entidades administrativas.

Los sistemas más frecuentes, como es de suponer, son las isolíneas 1(1) y las isopletas $1(2)$. Conceptualmente estos sistemas son iguales, delimitan

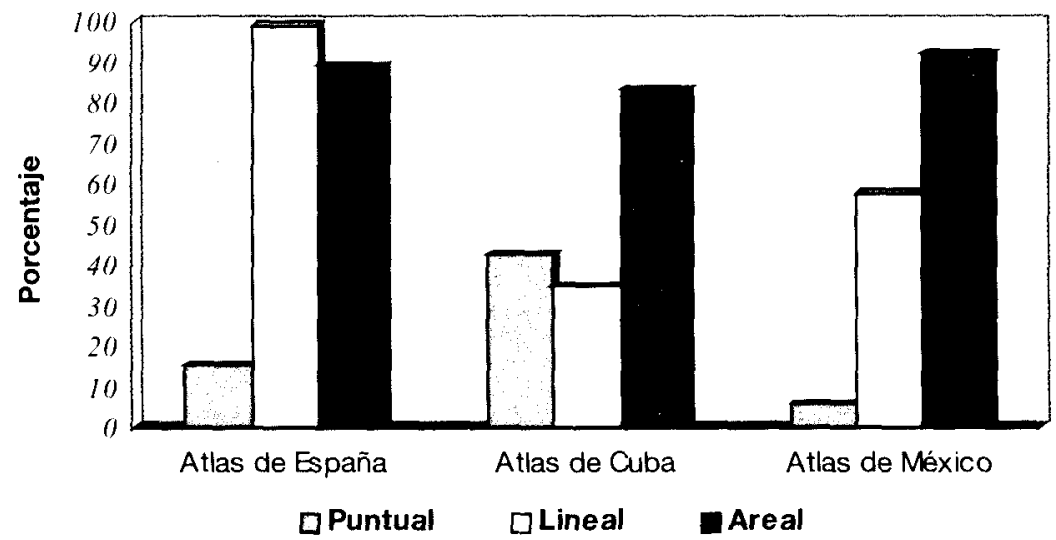

Gráfico 3. Relación porcentual de los sistemas de implantación. 


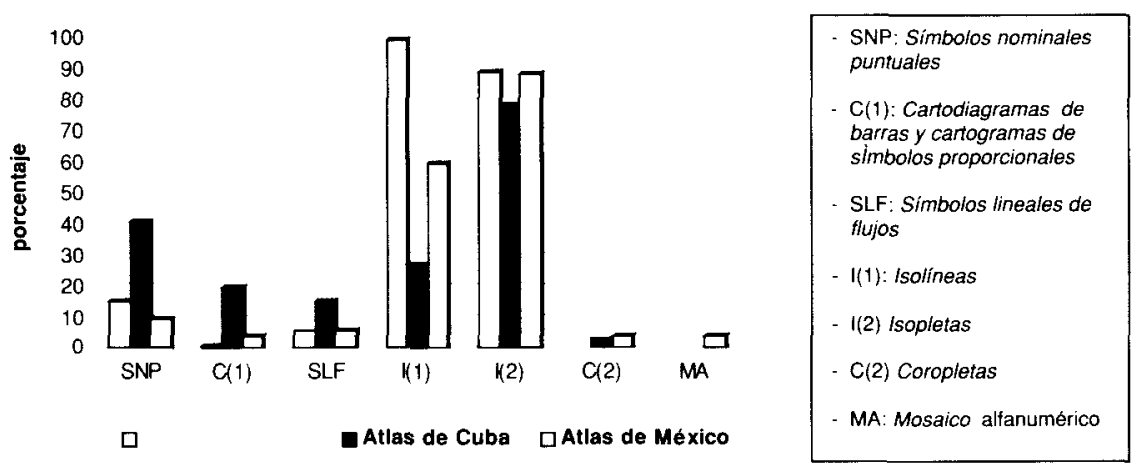

Gráfico 4. Relación de los distintos sistemas de representación.

superficies estadísticas, no obstante resulta interesante destacar cómo se han empleado en los tres Atlas. En el Atlas de España las isolíneas se utilizaron para reforzar o indicar el valor de las isopletas. La mayoría de los mapas de este Atlas tienen leyendas con más de diez rangos diferenciados por medio de la graduación de un tono o dos, al ser las diferencias de intensidades tan numerosas y cercanas unas de otras no es sencillo saber a qué rango pertenecen en el mapa; las isolíneas indican el valor del rango, facilitando así la lectura del mapa. En el Atlas de México las isolíneas delimitan áreas diferentes a las de las isopletas, es decir, los mapas con ambos sistemas de representación tienen dos contenidos asociados. $Y$ en el de Cuba las isolíneas se utilizaron para indicar rangos intermedios o aproximados que no se expresan con las isopletas, de esta forma se matizan esos valores intermedios que son producto de las diferencias altitudinales.

\subsection{Diseño Cartográfico y Características Técnicas}

Observamos en los diseños una adecuada esquematización y aprovechamiento al máximo de formatos, con una mayor variedad de distribuciones de los elementos gráficos en los Atlas de Cuba y México. Por no hacer excesivamente largo el comentario vamos a fijarnos especialmente en la composición de las páginas.

En los tres documentos predomina la distribución o composición simétrica, salvo en dos páginas del Atlas de España y en dos del Atlas de Cuba en las que la composición es áurea -división de un espacio, de manera general, en terceras partes tanto horizontales como verticales, consiguiendo así áreas estéticamente armónicas-. Para una de estas pá- 


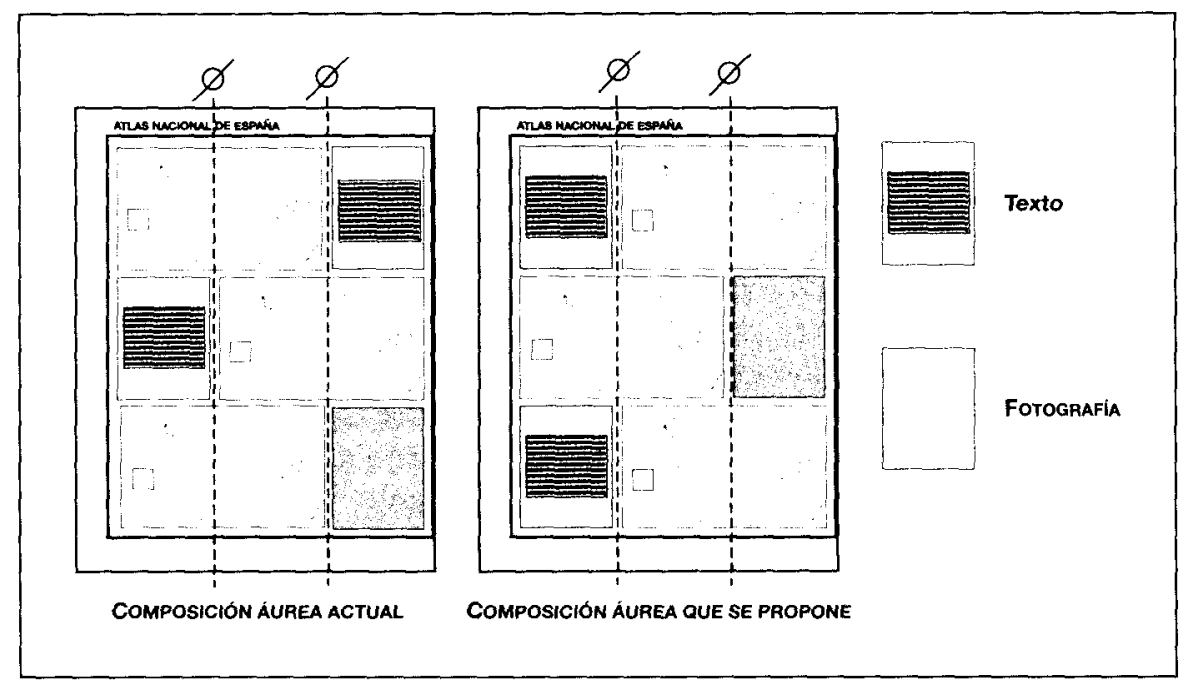

Fig. 9. Composición áurea, pág. 9.6 del ANE.

ginas del Atlas español de composición áurea proponemos mover los objetos como se observa en la figura 9. Esta nueva distribución equilibra la página ya que el peso gráfico de la fotografía es considerable.

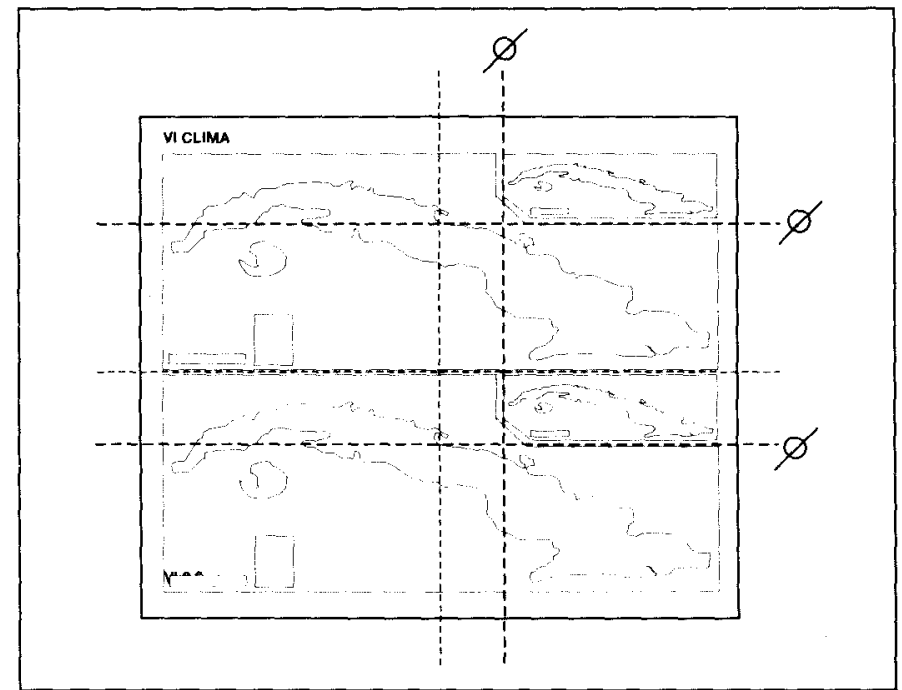

Fig. 10. Composición basada en la simetría y el espacio áureo, pág. VI.3.2 del NANC. 
En cuanto a las hojas del Atlas de Cuba, además del equilibrio áureo destaca la forma de algunas cajas, el diseño de éstas se ha ajustado a la forma del Archipiélago Cubano, con ello se consigue aprovechar al máximo el espacio de cada página o doble página en relación con las escalas de representación (fig. 10).

El aprovechamiento al máximo de espacios del Atlas de Cuba, trae como resultado que algunas páginas queden muy cargadas y su diseño sea poco atractivo. Comparando los diseños de los tres Atlas, los documentos español y mexicano son más agradables y simétricos. Se ha tenido un cuidado especial al organizar los elementos gráficos, incluso, en el Atlas de México la distribución de algunos se hizo no únicamente considerando el espacio disponible o establecido, sino que se tomó en cuenta el color y formato de los distintos mapas para equilibrar el diseño. Los ejemplos más representativos son la hoja de "temperaturas extremas" (ANM, p. IV.4.5) y la de "otros fenómenos climáticos» (ANM, p. IV.4.7) (fig. 11).

En términos generales los tres Atlas cumplen con la exigible cualidad de fácil lectura; no obstante hay algunos casos problemáticos para la retención de información o en la estimación de los valores, caso concreto el mapa de clasificación climática de México (ANM, p. IV.4.10) del que ya se habló anteriormente, o el de "precipitación media anual" de España (ANE, p. 9.5) en el que la separación de categorías no es sencilla por la

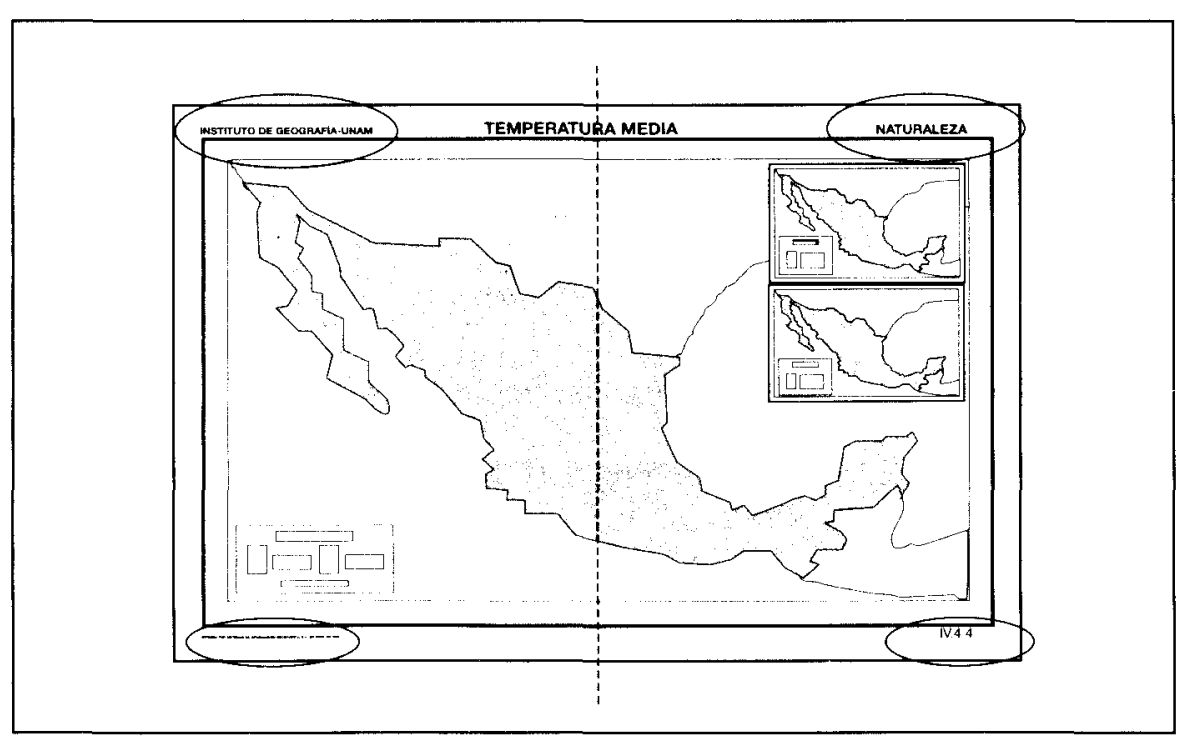

Fig. 11. Composición simétrica de la hoja N.4.4 del ANM. 
proximidad de los tramos distinguidos en la gama de valor. Otro mapa con problemas es el de «temperatura máxima absoluta anual del $5 \%$ de probabilidad" de Cuba (NANC, p. VI.3.1); en éste las tres primeras categorias se confunden entre sí. La deficiencia del mapa de España no es grave, ya que los autores, como se indicó antes, han incluido las isolíneas que son las guías complementarias para decodificar la información, pues sin ellas se presentarian serias dificultades de lectura.

Cabe por último, hacer referencia a las leyendas. En los mapas de España se emplearon las mismas gamas de color por parte de temas relacionados, esto favorece la comparación de mapas. En cambio en el Atlas de Cuba se elaboró una gama o paleta de color distinta para cada mapa, aun cuando se tratara del mismo tema representado, esta solución evita la monotonia del diseño, pero exige un mayor esfuerzo en la memorización por parte del lector.

\section{CONCLUSIONES}

La lectura cartográfica es para el profesor, y para cualquier usuario en general, uno de los mayores desafíos en el plano docente. ïodas aquellas materias que tienen un fuerte componente territorial precisan de análisis minuciosos y sistemáticos de los mapas. No resulta fácil encontrar referencias metodológicas claras que puedan ayudar en esta necesaria labor en el aula, en el gabinete técnico o en cualquier lugar donde se consulte un Atlas. La lectura inteligente de un mapa comporta el dominio de dos campos de conocimiento que confluyen en esa imagen cartográfica: el de los propios contenidos científicos expresados en el mapa y el referente al lenguaje visual y sus reglas de expresión. Cuando los mapas están organizados sistemáticamente en el Atlas la complejidad puede ser todavia mayor.

En este trabajo se propone un esquema de comentario - al que hemos llamado científico técnico- que puede resultar adecuado a la exploración cartográfica por parte de los usuarios, especialmente cuando éstos son estudiantes. Parece lógico abordar, en primer lugar, la estructuración de contenidos en su variedad y profundidad (aquí debe abrirse un horizonte amplio que permita el análisis temático interrelacionado, que en manera alguna se ha abordado en este trabajo); después, parece conveniente detenerse en ver cómo el cartógrafo ha resuelto presentar orgánicamente los contenidos, perfilando un hilo conductor del que derivan los aspectos específicos; más adelante, deben estudiarse las soluciones lingüisticas, viendo la atribución de variables visuales y los sistemas de representación; por último, los aspectos formales y de diseño merecerán la atención. 
Quiere ser, por tanto, esta aportación una herramienta que de manera inteligente puedan utilizar todos aquellos que con una actitud científica se enfrenten a los mapas o los atlas temáticos. De manera especial hemos tenido en cuenta la vertiente didáctica que encierra valores muy importantes de cara a la formación de los estudiantes.

\section{REFERENCIAS BIBLIOGRÁFICAS}

Atlas Nacional de España (1992-98): Ministerio de Obras Públicas, Transportes y Medio Ambiente, Dirección General del Instituto Geográfico Nacional, 5 tomos, Madrid.

Atlas Nacional de México (1990): Universidad Autónoma de México, 3 tomos, México.

CARTWRIGTH, W. (1996): "A Metaphor Set for User Access to Multimedia Mapping Products", in Proceedings of the Seminars on Electronic Atlases II, ICA, Prague, págs. 41-55

CARTWRIGTH, W. (1997): "The Application of a New Metaphor Set to Depict Geographic Information and Associations", in Proceedings of $18^{\text {th }}$ International Conference, Gävle, Sweden, vol. II, págs. 654-662.

- (1998): “Can the Map Metaphor Be Extended Using Web Delivered Multimedia? Research Questions for Multimedia Cartography", in http://www.Is.rmit.edu.au/landinfo/staff/ws/ icawg/com geo/com geo.html.

DoRLING, D. y FAIRBAIRN, D. (1997): Mapping: Ways of Representing the World, Longman, Great Britain.

KraAk, M. and Driel R. (1997): «Principles of Hypermaps», in http:/www.elsevier.nl/homepa$\mathrm{ge} / \mathrm{misc} / \mathrm{cageo} / \mathrm{hypermap}$.

- and KLOMP, A. (1998): "A Classification of Cartographic Animations: Towards a Tool for the Design of Dynamic Maps in a GIS Environment", in http://nvkserver.geoge.uu.nl/html/ nvk/ica.

- and Ormeling, F. (1996): Cartography. Visualisation on Spatial Data, Longman, London.

KryGieR, J. (1996): "Geography and Cartographic Design», en Wood and Keller, Eds., Cartographic Design. Theoretical and Practical Perspectives, Wiley \& Sons, England, págs. 19-34.

MiRANDA, R. y SANCHO, J. (1999): Propuesta metodológica para el análisis cartográfico: Ejemplo de apreciación de la variable temática "clima" en los Atlas Nacionales de España y Cuba. Espacio Tiempo y Forma, revista de la Facultad de Geografía e Historia, UNED, serie VI, Geografía, Tomo 12, Madrid, págs. 123-143.

- (2000): El Clima en los Atlas Nacionales de España y Cuba: Análisis Crítico desde una Perspectiva Cartográfica, Tesis Doctoral, Universidad de Alcalá, Departamento de Geografía, Madrid.

- y ECHAMENDI, P. (2000): “Representación del turismo a través del mapa: propuesta sintáctica y comentario de ejemplos", Mapping, N. ${ }^{\circ}$ 70, mayo. Madrid, págs. 14-26. http://WwW. mappinginteractivo.com.

Nuevo Atlas Nacional de Cuba (1989): Instituto de Geografía de la Academia de Ciencias de Cuba, Instituto de Geodesia y Cartografía, La Habana.

PARSONS, E. (1994): "Visualisation Techniques for Qualitative Spatial Information», en EGIS, Kingston, págs. 407-415.

Peterson, M. P. (1995): “Trends in Internet Map Use", in Proceedings of $18^{\text {th }}$ International Conference, Gävle, Sweden, vol. II, págs. 1635-1642.

- (1995): Interactive and Animated Cartography, Prentice Hall, New Jersey.

- (1998): "The Future of Animated Maps", as part of requirements for Advanced Cartographic Methods, in http://maps.unomaha.edu/peterson/methods/Research/Zale/Future.html.

TAYLOR, F. (1996): "Challenge an Response in Cartographic Design", en Wood and Keller, Eds., Cartographic Design. Theoretical and Practical Perspectives, Wiley \& Sons, England, págs. 11-18.

- et., al. (1985): Education and Training in Contemporary Cartography, Wiley \& Sons, England.

- et., al. (1996): “Design an Production of the Electronic National Economic Atlas of China (ENEAC)", in Proceedings of the Seminars on Electronic Atlases II, ICA, Prague, págs. 7-10. 